\section{EMBRYARIDDLE}

Aeronautical University

SCHOLARLY COMMONS
Journal of Aviation/Aerospace

Education \& Research

Volume 22

Number 1 JAAER Fall 2012

Article 1

Fall 2012

\title{
Analysis of General Aviation Instructional Loss of Control Accidents
}

Sarina J. Houston

Robert O. Walton

waltonr@erau.edu

Bruce A. Conway

Follow this and additional works at: https://commons.erau.edu/jaaer

\section{Scholarly Commons Citation}

Houston, S. J., Walton, R. O., \& Conway, B. A. (2012). Analysis of General Aviation Instructional Loss of Control Accidents. Journal of Aviation/Aerospace Education \& Research, 22(1). https://doi.org/10.15394/ jaaer.2012.1402

This Article is brought to you for free and open access by the Journals at Scholarly Commons. It has been accepted for inclusion in Journal of Aviation/Aerospace Education \& Research by an authorized administrator of Scholarly Commons. For more information, please contact commons@erau.edu. 


\title{
ANALYSIS OF GENERALAVIATION INSTRUCTIONAL LOSS OF CONTROL ACCIDENTS
}

\author{
Sarina J. Houston, Robert O. Walton, and Bruce A. Conway
}

\begin{abstract}
Although student pilots spend many hours practicing maneuvers to improve airmanship and prevent accidents, almost one half of all general aviation aircraft accidents occur during flight training. Among these, loss of control is the most commonly cited causal factor, and the most common first occurrence in a chain of causal events. This project answers the following question: Can an analysis ofNational Transportation Safety Board (NTSB) accident reports identity the role of secondary causal factors or reasons involved in general aviation loss of control accidents that involve instructional flights? The analysis focuses on five factors as they each relate to loss of control events: causal factors, phase and location of flight, student and instructor experience, procedural errors, and meteorological conditions. In addition, common occurrences were analyzed to determine trends involved with accident chains of events, and a chisquare test was completed for student and instructor experience as well as accident locations in order to gather insight and support recommendations regarding instructional loss of control accidents in general aviation. The study revealed at least two significant findings: (1) the number of student flight hours accumulated correlates to accident location; and (2) the chain of events in an accident can be an important piece of information in determining causes of an aircraft accident.
\end{abstract}

\section{Introduction}

Safety experts within the general aviation community are constantly working toward an accident-free flying environment. While the industry has made vast improvements in the past years to reduce the accident rate, there is still much that can be done to further advance safety in the general aviation community (Wood \& Sweginnis, 2007). These safety measures can, and should, begin during initial pilot training. A student pilot spends much of his or her initial training time practicing maneuvers and techniques such as takeoffs, landings, traffic patterns, stall prevention, unusual attitude recovery, and others (U.S. Department of Transportation, Federal Aviation Administration, 2002).

This research examined the National Transportation Safety Board database of aircraft accidents to determine the common causes of general aviation flighttraining accidents that involve loss of control in an effort to provide feedback to the general aviation community regarding potential improvements that can be made. Although student pilots spend many hours practicing maneuvers to improve airmanship and prevent accidents, flight-training accidents still occur. Among these, loss of control is the most commonly cited causal factor (National Transportation Safety Board [NTSB], 2009). The purpose of this research was to determine which factors contribute to loss of control during flight training accidents in order to help general aviation pilots understand and prevent these occurrences.

According to the NTSB (2010), over one half of all flight training accidents in 2006 involved loss of control either on the ground or in flight. Loss of control was the most commonly cited factor in general aviation accidents overall, a result that is perhaps carried over, at least in part from poor flight training practices (NTSB, 2010). Considering that the general aviation accident rate increased from 2004-2005, and the fatality rate further increased in 2006, one can speculate that there remains insufficient focus on general aviation accident prevention (NTSB, 2009, 2010). The Federal Aviation Administration (FAA) and NTSB both monitor trends and make recommendations to 
Journal of Aviation/Aerospace Education \& Research, Vol. 22, No. 1 [2012], Art. 1

general aviation pilots, flight instructors, and training centers through bulletins and seminars, but the vast array of flight instructors and flight schools may make the continuous tracking of flight-training methods and results difficult. Additionally, aviation industry leaders tend to focus their safety efforts and resources on the most harmful accidents in terms of damage and injury, which tend to be commercial aircraft accidents (Wood \& Sweginnis, 2007).

If one stops to consider that, according to the NTSB (20 I0), the leading cause or factor involved in all aircraft accidents are human factor related, and that good piloting skills are learned from the beginning stages of training, one can assume that better flight training in general aviation can potentially improve the aviation industry accident rate overall. A better understanding of the underlying problem or problems involved in flight training accidents can potentially reduce risks involved in the flying environment for future pilots. Through research and awareness, flight training can become safer for students and instructor pilots, in turn creating a safer flying environment for all pilots.

Data for this study were extracted through the NTSB 's online query form for accidents, and limited to dual and solo general aviation flight-training accidents occurring between January I, 2000 and December 1, 2009. Reports analyzed included only fixed-wing aircraft registered in the United States, and always included a dual training flight or supervised solo flight in which loss of control was cited as a causal or contributing factor. The NTSB produces both preliminary findings and fmal reports for every accident. The data associated with this research were limited to fmal, published accident reports from the public NTSB database. Since accident investigations take time, reports from many ofthe most recent accidents (20 10-20II) were not available in a final form; thus, the most current results used were from 2009.

This study is based solely on data extracted from NTSB accident reports; thus, the researchers have assumed that the flight data reported on the NTSB reports is accurate and that reporting methods remained consistent between 2000 and 2009. While many of the requirements for reporting are specific, a self-reporting bias exists due to the human element involved in the personal narrative portion of the report.Much of the data can be verified, such as weather or runway conditions at the time of the accident. The pilot's narrative, however, cannot be verified in a meaningful way.

\section{Research Question}

Can an analysis ofNTSB accident reports identify the role of secondary causal factors or reasons involved in general aviation loss of control accidents that involve instructional flights? An analysis of the NTSB accident database found that there are significant factors that contribute to loss of control events in-flight-training accidents. The following causal factors were analyzed: location and phase of flight, student and instructor experience, specific procedural errors when applicable, and meteorological factors. Additionally, accident occurrences were recorded in the order that each occurred, and analyzed for trends associated with order of occurrence and specific sequences of events.

With prior knowledge and data observed, one can interpret that the majority of loss of control accidents occur due to stalls/spins in maneuvering flight, and lack of directional control during the takeoff and landing phases of flight. It is assumed that most accidents involve less experienced pilots; however, this may not be the case. Inthe event that trends are noted, procedural errors in flight training are of importance for future recommendations; a preliminary hypothesis can be made citing the lack of correct recovery procedures from maneuvers such as a balked landing, etc. Weather factors should only play a small role in this study, as most flight training operations are conducted on good-weather days.

Brief Review of the Literature

A literature review revealed extensive data regarding general aviation accidents, including statistics surrounding the causal factors, types of operations, aircraft types, etc. Current research associated with flight training accidents is less common; as such, specific reasons behind many flight training accidents remain unknown. Perhaps this is due to lack of reporting details, the wide industry focus on transport aircraft and operations, or perhaps it is because of the lack of resources available to general aviation companies and institutions regarding aircraft safety. Still, general aviation accident statistics exist, courtesy of the NTSB accident and incident database, which will be discussed in the following paragraphs .

The NTSB provides an annual review of aircraft accident data. In 2005, the NTSB reported a total of I,670 general aviation accidents, a $3 \%$ increase from the previous year (NTSB, 2009, 20IO). The accident rate among instructional flights is only about $34 \%$ of all GA accidents, one half that of personal and business flying (NTSB, 2009). In 2006, the number of total accidents dropped 9\%, and instructional accidents remained at about half that of personal and business flying (NTSB, 20 I 0). As a significant portion of accidents in this category, it would be beneficial to minimize the instructional accident percentage as much 
as possible. One way to minimize the accident risk is to fmd the cause or causes involved.

Causes of flight training accidents can be categorized into three broad categories \{more than one category can be cited for an accident): human, environment, and aircraft (NTSB, 2009). Human error make up 95\% of causes of instructional flight accidents (NTSB, 2009). Environmental causes of accidents \{due to marginal weather) are rare in flight training due to the majority of flight training accidents conducted during good weather operations (NTSB, 2009). Aircraft-related causes are represented in only $13 \%$ of instructional flights and are composed of such things as engine failure, gear malfunction, etc. (NTSB, 2010). The fact that 95\% of flight training accidents can be attributed to human error is significant, and tells us that the key to accident prevention is the recognition of these errors during early flight training. "Of the 1,228 accidents in 2006 with a human performance cause or factor, the most frequently cited cause/factor was aircraft handling and control (71\%)" (NTSB, 2010, p. 48).

Of the accidents categorized as human error, the most frequently cited causal factor was loss of control (NTSB, 2010). Moreover, "loss of control in flight" and "loss of control on ground" were the two most commonly cited chains of occurrences contributing to the accident (NTSB, 2010). The broad category of causal factors (human, environment, and aircraft) can further be divided into contributing factors, such as stall/spin, loss of directional control, engine failure, improper procedures, etc., as shown in the author's data. The lack of current studies on these specific factors suggests that the reasons behind loss of control during instructional flights are still unknown . Accident data imply that preventing loss of control events in instructional flights remains an underemphasized piece of flight training. While flight students are taught stall awareness and recovery, stalls and spins are still a common cause of loss of control accidents (NTSB, 2009, 2010). The large number of loss of control events may not improve without the proper attention to accident prevention. While the emphasis on Technically Advanced Aircraft (TAA) and the Next Generation Air Transportation System (NextGen) safety is important, the need to address actual accident causes and deficiencies in-flight training still remains.

\section{Methodology}

Descriptive and quantitative models were used to analyze data during this research project. Data from the NTSB Accident and Incident Database were analyzed and quantified in an MS Excel database. A descriptive analysis was accomplished through supporting facts discovered through the data analysis and accident narratives.

Data were collected on a spreadsheet created by the researchers to organize and analyze appropriate pieces of information extracted from the NTSB accident reports. Each accident report was frrst analyzed for specific factors, such as causes, accident location, student and instructor experience, weather conditions, etc. The data include the following information:

- General information (accident report number, accident date, fatalities);

- Collision location \{ on ground or in flight);

- Probable cause (failure to ensure terrain clearance, failure to maintain airspeed, failure to maintain directional control, improper flap setting, stall/spin, maintenance problem, inadequate supervision, improper procedure, lack of experience);

- Phase of flight (takeoff, climb, enroute, maneuvering, approach or descent, landing, goaround, taxi);

- Total student flight times \{total and total in accident aircraft);

- Total instructor flight times (total and total in accident aircraft):

- Solo or dual flight status;

- Weather \{Visual Meteorological Conditions (VMC)/Instrument Meteorological Conditions (IMC), wind velocities and night/day).

Both a descriptive and statistical analyses was performed using the results of the data and a chi-square test. First, the total number of the above listed factors were recorded and compared with each accident's causal factor(s) to determine the relationship between them. For example, accidents with loss of control cited as a first or subsequent occurrence were compared to level of experience, phase of flight, etc., to determine a correlation, if any, between the two.

The absence of numerical values for much of the data suggested that a nonparametric test such as the chisquare test would be most useful. The researchers used a chi-square test on two sets of data: $\{$ a) instructor flight times (0-1499 hours and 1500 or greater hours logged) and accident location (on ground accidents and in air accidents), and (b) student flight times (0-49 hours and 50 or greater hours logged) and accident location (on ground and in air accidents). To perform the chi-square test, categorical data from a random sampling of the accident reports were laid out in a contingency table for each set of data (see Appendix A). 
Because the expected values for the data are unknown, they were computed assuming no association between the datasets. Second, the researchers identified common causes associated with loss of control accidents and any relevant supporting data. To accomplish this, specific occurrences were coded and chains of occurrences identified for each accident when enough information was given. The first occurrence was noted, along with any other occurrences given in the accident report, up to five occurrences. Occurrences were categorized in one of 17 categories, such as loss of control in flight, loss of control on ground, in flight collision with object/terrain/Non-CFIT, ground collision with object/terrain/Non-CFIT, in flight encounter with weather, hard landing, abnormal runway contact, stall/spin, preflight event, gear collapse, system fail, power loss (partial), power loss (total), nose over, forced landing, mise/other.

Trends involving occurrences (for instance, a high occurrence of stalls/spins, followed by loss of control, followed by a crash), were documented. Out of the 147 reports analyzed the authors identified 11 common chains of occurrences (in which a chain of occurrence is at least two occurrences) and further narrowed the results to two or three frequent reasons behind the loss of control occurrence, in order to gain further insight into the cause behind frequent loss of control accidents.

\section{Results}

An examination of 147 general aviation instructional accidents involving loss of control was completed. Of these, almost $75 \%$ cited "loss of control" as the first occurrence in the accident. Further, approximately $60 \%$ of the events citing loss of control as a first occurrence happened in-flight (such as during a stall or maneuver), and $40 \%$ of the events happened on the ground (such as taxi or takeoff roll). Of the remaining 46 accidents analyzed, loss of control was recorded as a second, third, or fourth occurrence (see Appendix B).

Figure 1 depicts the most common causal factors involved in loss of control accidents. The factors listed in Figure 1, while numerous, are only the most common occurring factors in the accidents studied for this research.

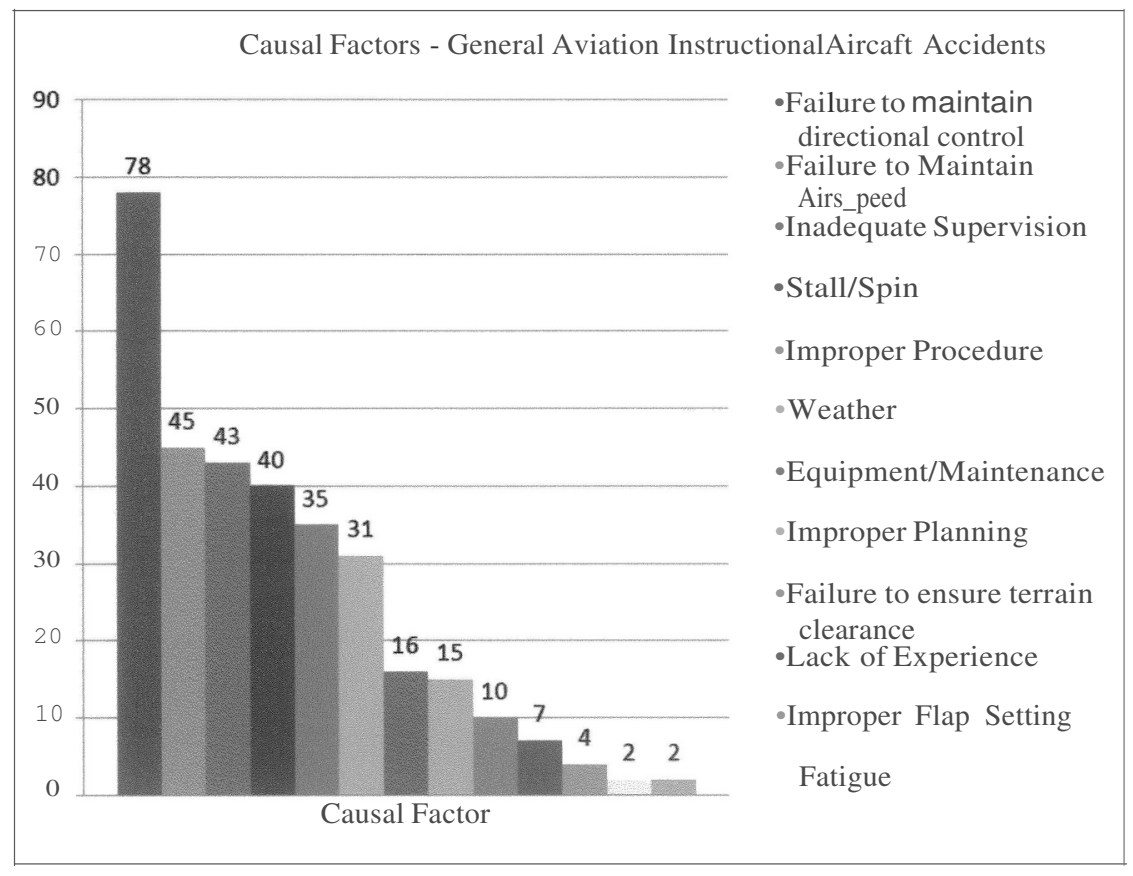

Figure 1. Frequency of reported causal factors in general aviation instructional loss of control accidents. Multiple factors are usually reported for a single accident. 
The most commonly reported causal factor of accidents in this study involves loss of directional control, with 78 reported cases (53\%). Failure to maintain airspeed, inadequate instructor supervision, stall/spin, improper procedure, and weather are the next most common factors, followed by equipment problems, improper planning, and failure to ensure terrain clearance. Lack of experience, improper flap setting, fatigue, and medication side effects contributed to a small number of accidents.

A significant number of accidents occur during takeoff, landing and go-around phases of flight, as depicted in Figure 2. By far, the highest number of accidents occurred during the landing phase of flight, followed by maneuvering, takeoff, climb, and go-around phases, respectively.

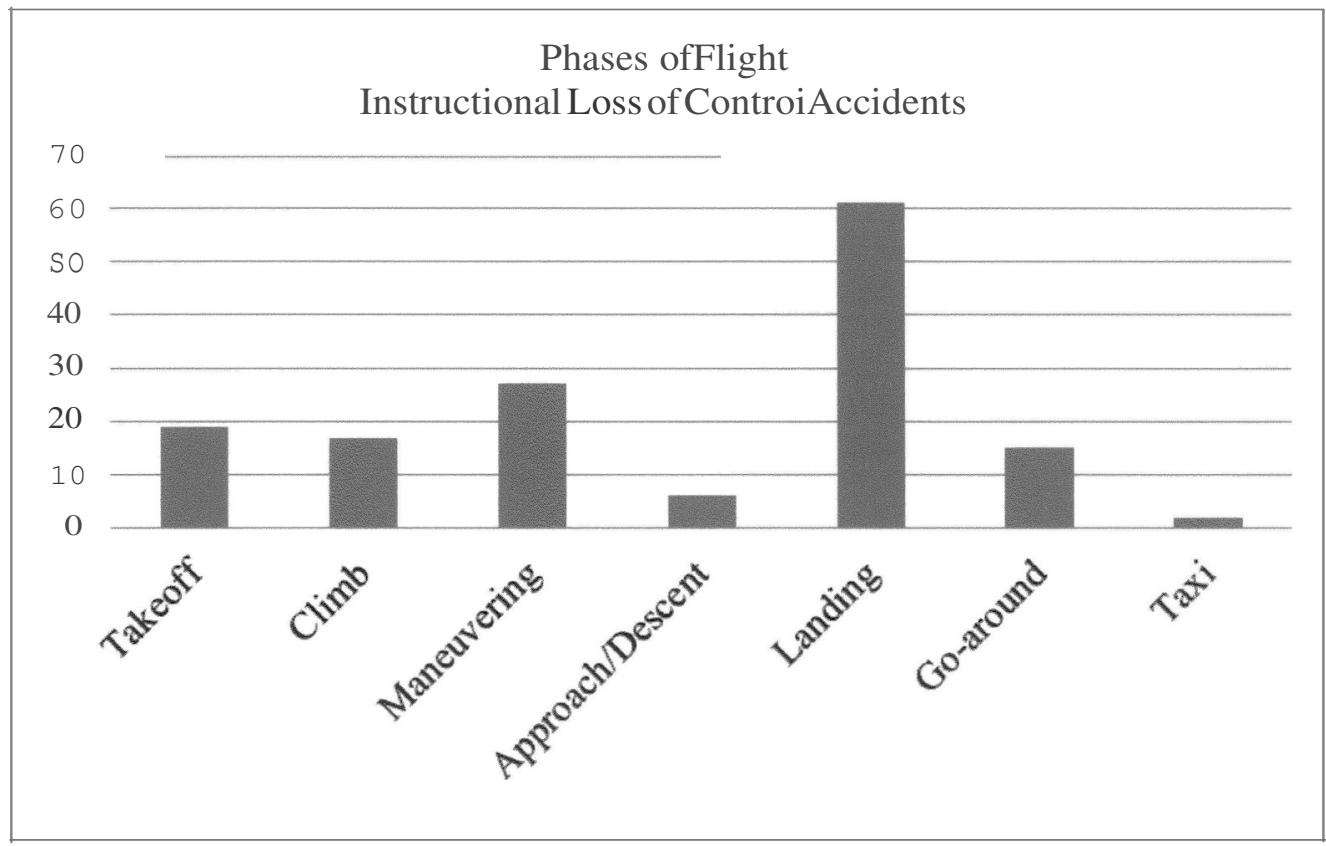

Figure 2. Phases of flight during which general aviation instructional loss of control accidents occur. 
A high percentageof accidents in this study occurred during the day, with visual meteorological conditions prevailing, and light winds. Figure 3 shows that only four accidents of the 147 that were analyzed reportedly occurred at night, and 136 during the day (note: the data were not available for all reports reviewed). Three accidents occurred during instrument meteorological conditions (IMC) and 141 during visual meteorological conditions (VMC). Eighty-five accidents occurred with associated wind speeds of less than 10 knots and $95 \%$ of all the recorded accidents occurred when the wind speed was less than 20 knots.
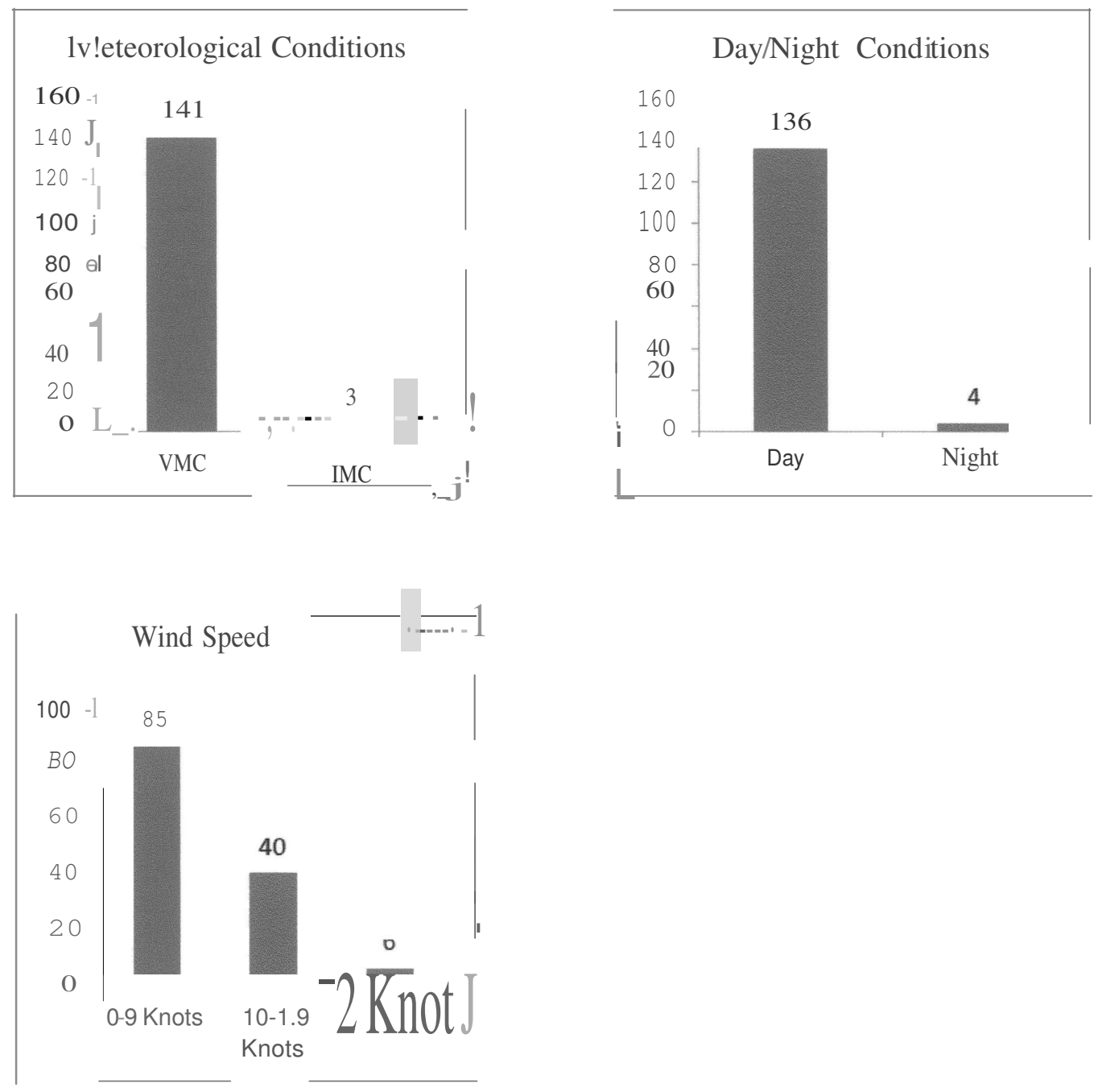

Figure 3. Weather occurrences for general aviation loss of control accidents, as reported in NTSB accident reports. 
The student data used in this study is not limited to student pilots obtaining an initial pilot certificate, but pertains to all flight training students and events. Student and instructor experience varies in relation to accidents. Perhaps obvious is the fact that less experienced students are involved in most of the accidents recorded. Figure 4 details the results of 91 accident reports that reported student flight hours. Eighty percent of the student pilots had logged less than 50 hours of flight time in the accident aircraft, and $48 \%$ of student pilots had logged less than 50 hours total. Approximately $10 \%$ of the accidents involved students who had accrued more than 500 hours, with the remaining $42 \%$ falling between 50 and 499 hours.

Conversely, 66\% of instructors involved in loss of control accidents had over 1,500 hours of experience, although not always in the accident aircraft. Only about $11 \%$ of instructors had less than 500 hours total. Instructor experience in the accident aircraft shows a similar correlation: approximately $23 \%$ of instructors had accrued less than 50 hours, $31 \%$ had between 50 and 249 hours, and the remaining $45 \%$ had logged over 250 hours in the accident airplane.

\section{Flight Times and Accident Locations}

Itis important to note the correlation between flight times and the accident location to further identify the areas at risk for loss of control during instructional flights. To do this, a chi-square test was performed on a random data sampling of student flight times and accident location, as well as instructor flight times and accident location.For the first test, a random sampling of 50 reports were taken from the pool of 81 accidents for which student flight time was reported, and the accident location (either in flight or on ground) was tested against two values: students with fewer than 50 hours of flight time and students with 50 or more hours of flight time logged at the time of the accident. 

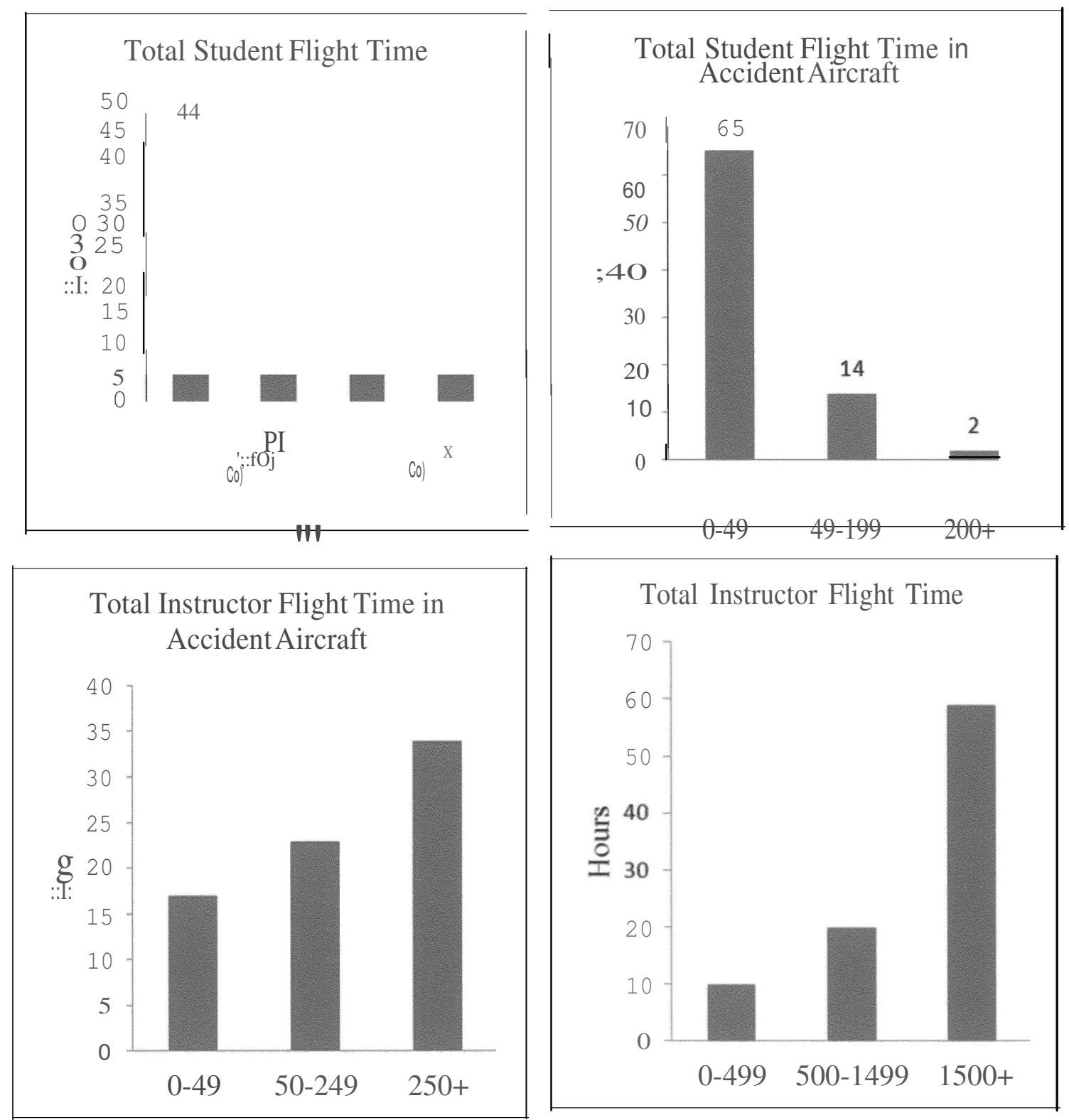

Figure 4. Student and instructor flight experience. Total flight hours logged is shown, as well as total time logged in accident aircraft. 
The chi-square test for total student flight time as it correlates to accident locations was statistically significant, $X^{2}=9.8, \mathrm{p}=.0015, d f=1$. The results show more than a $99 \%$ probability that there is a true difference between student flight experience (hours of flight accrued) and accident location (in flight or on ground). A chi-square test for instructor experience with values of 0-1499 total flight hours and 1500 or more flight hours was conducted, the results were not statistically significant, $X^{2}=2.96, p=$ $.85, d f=1$.

\section{Occurrence Sequences}

The third stage of the research involved detecting common chains of occurrences, or sequences, involved in instructional loss of control accidents. The authors discovered that there were a multitude of accident reports that failed to go into detail regarding event occurrence.

The complete list of common sequences found can be viewed in Table 1. At 44\%, the most common sequence discovered was "loss of control, in flight" paired with "inflight collision." Second most common was "loss of control, on ground" and "ground collision." The remaining sequences are possibly more descriptive, as they begin to illustrate other events that occurred prior to the loss of control event, as witnessed in the third most common sequence: "in-flight encounter with weather" plus "loss of control, in-flight," plus "in-flight collision." While $71 \%$ of accidents fell under the first two sequence pairs, the remaining list provides further insight which will be discussed more in depth in the next section.

Table 1

Common accident occurrence sequences

\begin{tabular}{lllr}
\hline Occurrence I & Occurrence 2 & Occurrence 3 & Total \\
\hline Loss of control-In flight & In-flight collision & & 44 \\
Loss of control-On ground & Ground collision & In- flight collision & 31 \\
In-flight encounter with weather & Loss of control-In flight & & 6 \\
Loss of control-On ground & Nose over & Ground collision & 5 \\
Loss of control-In flight & In- flight collision & & 4 \\
Loss of control-In flight & Ground collision & Ground collision & 3 \\
Loss of control-On ground & Gear collapse & Nose over & 3 \\
Loss of control-On ground & Ground collision & Ground collision & 3 \\
Loss of control-In flight & StalVspin & In-flight collision & 2 \\
Hard landing & Loss of control-In flight & Nose over & 2 \\
Loss of control-In flight & In-flight collision & \\
\hline
\end{tabular}


Journal of Aviation/Aerospace Education \& Research, Vol. 22, No. 1 [2012], Art. 1

\section{Discussion}

The results from this study parallel results from the NTSB's 2006 review of accident data. In this study, for instance, the findings showed that $40 \%$ of loss of control events happened on the ground and $60 \%$ in the air. The NTSB claimed similar values: In 2006, the agency reported that $56 \%$ of in-flight events involved loss of control, and $56 \%$ of events on the ground involved loss of control. Overall, the most common causal factors in each study were similar, although this study examined more specific categories than the NTSB study. The NTSB found that the largest number ofhuman factor related issues involved with general aviation accidents overall are due to "aircraft handling/control." The data suggest similar fmdings: "Failure to maintain directional control" and "failure to maintain airspeed" were the most common causal factors in instructional loss of control accidents. Further, NTSB data reveal that $44 \%$ of instructional accidents occurred during the landing phase of flight, again mirroring this study with $42 \%$.

There were slight variations between the results pertaining to weather conditions, most likely an indication of the nature of instructional flights. Six percent of accidents occurred in IMC conditions in the NTSB study, while only $2 \%$ occurred in IMC conditions in this study. Night accidents occurred in $8 \%$ of the overall accidents in the NTSB study, versus only $3 \%$ in this study. This is most likely due to the sort of conditions that make up the majority of instructional flights-most instructional flights take place during day, VFR conditions, and in light wind; therefore, the majority of instructional accidents will occur during these conditions.

Flight Times and Accident Locations

Data surrounding student and instructor experience provide meaningful insight into instructional accidents. It is not surprising that instructional accidents involve low-time students. It is important to note the large decrease in accidents as a student gains experience in a particular aircraft. As discussed previously, after a student gains at least 50 hours experience in a single aircraft type, the accident occurrence rate sharply decreases. The data are important; it directs attention to accident awareness within thefirst 50 hours offlight, specifically.

Also noteworthy is that $66 \%$ of instructors involved in the dataset had accumulated over I,500 total hours of experience, challenging the idea that the more experience an instructor has, the less risk of an accident occurrence. The instructor experience data also lends itself to further research in order to determine trends among instructor experience and accident risk.

The results of the chi-square test for experience versus accident location determined that there is a true difference between student flight experience and accident location. The first test was statistically significant, $p=$ .0015 . Students with fewer than 50 hours are more likely to encounter a loss-of-control situation on the ground. Students with 50 or more hours of experience are more likely to encounter a loss of control event in flight. There was no correlation found regarding instructor experience and accident location. Although the data distribution showed that a large percentage ofhigh-time instructors (greater than 1,500 hours) were involved in accidents occurring in flight, the data were shown to be statistically random and therefore, insignificant.

Loss of control is the most common first occurrence stated in instructional accidents. Reasons behind the loss of control event were not always included in the accident report; therefore, the data are limited. However, the two most common sequences were (a) "loss of control-in flight" plus "in-flight collision,' and (b) "loss of control-on ground" plus "ground collision," neither of which provide information about why the loss of control event happened.

\section{Conclusions and Recommendations}

The quest for an accident-free aviation environment will never end. Minimizing risk and preventing accidents is the primary focus of most pilots and flight departments. Although each entity will employ its own method and program for aviation safety, each accident can be traced back to the training environment. Was the pilot trained properly? How experienced was he or she? How can procedures be improved opon to prevent loss in the future? These questions are always being examined.

This research has identified and expanded upon multiple areas of importance involved with instructional loss of control accident prevention. Loss of control is the most commonly cited causal factor and the most common first occurrence in all general aviation instructional accidents. Results show that these accidents are occurring both in flight and on the ground, in mostly good weather conditions. It is important to note that the majority of accidents when aircraft control is lost occur during the landing and maneuvering phases of flight, during day VFR conditions, and typically with wind speeds of less than 10 knots. Student experience follows an obvious trend: The more experience a student has accumulated, especially in type-specific aircraft, the less likely he or she is to be involved in an accident. Instructors, however, show an opposite correlation: In fact, the data in 
this study showed that $66 \%$ of instructors had over 1500 total hours of flight time, implying a higher risk for instructors with a higher number of hours. This risk decreases if the instructor has a higher number of hours in a type-specific aircraft.

The data in this study have revealed at least two significant findings:

1. The number of student flight hours accumulated correlates to accident location, exposing specific risks: students with less than 50 hours are more likely to experience loss of aircraft control on the ground, while more experienced students are more likely to lose control of the aircraft in flight.

2. The chain of events in an accident can be an important piece of information in determining causes behind the accident. Inthe case of this research, reasons behind loss of control accidents were not obvious, but common sequences of events were noted and particular events, such as an in-flight encounter with weather, were revealed and can be expanded on in further studies.

The research question in this study sought to determine if the analysis of NTSB accident reports can identifY the role of secondary causal factors or reasons involved in general aviation loss of control accidents that involve instructional flights. The results of the chi square test and the analysis of occurrence sequences indicate that accident analysis can, indeed, reveal causal factors associated with these accidents. Although not considered a cause, per se, student experience proved to be a noteworthy factor in instructional accidents. The chi square test revealed that students with less experience were more likely to have an on-ground collision, for instance.

Specific causal factors for instructional loss of control aircraft were identified through the analysis of accident occurrences and related sequences. The sequences expose the most common occurrences, or causal factors, involved in instructional loss of control aircraft accidents at the most basic level. Since the majority of the accident sequences failed to move beyond the descriptive terms "loss of control" either on the ground or in flight, however, the majority of the accident data failed to provide useful information in this regard. The remaining data do provide insight into specific causal factors (i.e., in-flight encounter with weather); however, this number of accidents that provided detailed descriptive causal factors is inadequate for analysis in this study. A larger dataset is needed to provide sufficient evidence of overall characteristics, but the results, while simple, provide a premise for further study, and prove that analysis of NTSB accident reports can certainly determine causal factors involved in instructional loss of control aircraft accidents.

As accident investigation methods and techniques continue to improve, further research can be facilitated to determine the causes of instructional loss of control accidents. Accident causes are complex, and require timeconsuming research. This study has shown that trends do exist, and instructional methods can be improved upon in order to reduce general aviation accidents, specifically involving common loss of control situations.

The authors recommend that the FAA revise the flight training standards at regular intervals to include areas of focus necessary from recent accident data observations. With the knowledge that most students with fewer than 50 hours of flight experience encounter loss of control on the ground might be cause for a greater focus on taxi, takeoff, and landing training and techniques in the early portion of training. Subsequently, more experienced pilots tend to be more comfortable with taxi, takeoff, and landings and should perhaps focus on safety during maneuvers, stalls, and spin training. At least one specific area of concern is associated with in-flight encounters with weather. Several accident pilots reported wind conditions associated with loss of control, and this is an important topic to consider with new flight students.

The NTSB continues to improve upon accident reporting methods and accident investigation methods. The reporting methods should continue to become more consistent and more specific. The sequence 'loss of control' followed by 'collision in flight' is not comprehensive enough to provide the insight needed for accident prevention. Itis the authors' opinion that the continuation of the "first occurrence" method is important, as is the recording of second, third, and fourth occurrences, until the question "why?" can be answered for every accident that occurs. Only then will the industry be able to close the gap created from the human factor risk involved in aviation. Perhaps the most difficult aspect of flight training accident prevention revolves around long-term standardized procedures put in place by the FAA years ago, which also shapes a cultural environment that is difficult to change. While the aviation industry has certainly changed in recent years, the FAA's practical test standards for private, commercial, and instrument pilot applicants have not kept pace. The recent addition of the FAA/Industry Training Standards (FITS) program, which introduces a new approach of situational-based training in addition to maneuvers-based training, is a start to the much-needed change in methods. While it is a start, the FAA and other 
Journal of Aviation/Aerospace Education \& Research, Vol. 22, No. 1 [2012], Art. 1

Loss of Control Accidents

industry partners should act quicker to keep up with the fast-

changing aviation environment.+

Sarina Houston holds a Master of Aeronautical Science degree from Embry-Riddle Aeronautical University, and is a FAAcertified commercial pilot and flight instructor.

Robert Walton is an Assistant Professor of Business and Associate Dean of Academic Support European Region and holds a $\mathrm{Ph} . \mathrm{D}$. in Business Administration, a Master of Business Administration, and a Master of Aeronautical Science. Robert teaches and conducts research on various aeronautical and related subjects at Embry-Riddle Aeronautical University- Worldwide.

Bruce Conway holds a Master of Science in Aerospace Engineering and a Ph.D. in Engineering Management, and is the Chair of the Department ofEngineering Sciences at Embry-Riddle Aeronautical University- Worldwide. Before shifting from adjunct to full-time faculty at Embry-Riddle, Bruce retired as the Chief of the Instrument Research Division at NASA- Langley. Bruce teaches and conducts research on various aeronautical and related subjects atEmbry-Riddle Aeronautical University-Worldwide. 


\section{References}

National Transportation Safety Board. (2009). Annual review of general aviation accident data 2005. (Annual Review NTSB/ARG-09/01). Washington, DC:Author.

National Transportation Safety Board. (2010). Annual review of general aviation accident data 2006. (Annual Review NTSB/ARG-10/01). Washington DC: Author.

National Transportation Safety Board. (n.d.).Aviation accident database and synopses. Retrieved from http $/ /$ www.ntsb.gov/ntsb/query .asp\#query_start

U.S. Department of Transportation, Federal Aviation Administration .(2002). Private pilot practical test standardsfor AIRPLANE (SEL, MEL, SES, MES) (FAA-S-8081-14A with Change 1). Retrieved from

http $/ /$ www faa.gov/training_testingl testing/airmen/test_standards/pilot/media/F AA-S-8081-14A.pdf

Wood, R., \& Sweginnis, R.(2007). Aircraft accident investigation (2nd ed.). Casper, WY: Endeavor Books. 
Journal of Aviation/Aerospace Education \& Research, Vol. 22, No. 1 [2012], Art. 1

\section{Appendix A}

Contingency Tablefor Accident Location

\begin{tabular}{|c|c|c|c|c|c|}
\hline \multirow[b]{2}{*}{ Student flight time } & \multicolumn{2}{|c|}{ In-flight } & \multicolumn{2}{|c|}{ On-ground } & \multirow[b]{2}{*}{ Total } \\
\hline & Observed & Expected & Observed & Expected & \\
\hline$<50$ Hours & 9 & 15 & 18 & 12 & 27 \\
\hline$>50$ Hours & 18 & 12 & 5 & 11 & 23 \\
\hline \multirow[t]{2}{*}{ Total } & 27 & & 23 & & 50 \\
\hline & $0-E$ & $\begin{array}{c}\text { Yates } \\
\text { correction (- } \\
.05\}\end{array}$ & $\left\{0-E Y^{\prime} 2\right.$ & $\{O-E\} 2 / E$ & \\
\hline$<50$, in-flight & 6 & 5.5 & 30.25 & 2.02 & \\
\hline$<50$, on-ground & 6 & 5.5 & 30.25 & 2.52 & \\
\hline$>50$, in-flight & 6 & 5.5 & 30.25 & 2.52 & \\
\hline \multirow[t]{2}{*}{$>50$, on-ground } & 6 & 5.5 & 30.25 & 2.75 & \\
\hline & & & hi Square & 9.81 & \\
\hline
\end{tabular}


Appendix B

Accident Events in Order of Occu"ence

\begin{tabular}{|c|c|c|c|c|c|}
\hline & First & Second & Third & Fourth & Fifth \\
\hline Loss of control- in flight & 65 & 16 & 6 & & 0 \\
\hline Loss of control- on ground & 45 & 5 & & 0 & 0 \\
\hline In-flight collision $\mathrm{w} /$ terrain & 3 & 55 & 18 & 7 & \\
\hline On ground collision $\mathrm{w} /$ terrain & 0 & 40 & 14 & & 0 \\
\hline In-flight encounter with weather & 7 & 0 & 0 & 0 & 0 \\
\hline Hard Landing & 9 & 2 & 0 & 0 & 0 \\
\hline Abnormal Runway Contact & 2 & & 0 & 0 & 0 \\
\hline Stall/Spin & & 2 & 0 & 0 & 0 \\
\hline Preflight Event & 2 & 0 & 0 & 0 & 0 \\
\hline Gear Collapse & 1 & 5 & 3 & 0 & 0 \\
\hline System Failure & 4 & 0 & 0 & 0 & 0 \\
\hline Partial Power Loss & & 2 & 0 & 0 & 0 \\
\hline Full Power Loss & 4 & & 0 & 0 & 0 \\
\hline Nose Over & 0 & 6 & 0 & 0 & 0 \\
\hline Forced Landing & 0 & 3 & 0 & 0 & 0 \\
\hline Other & 3 & 2 & 0 & 0 & 0 \\
\hline
\end{tabular}


Journal of Aviation/Aerospace Education \& Research, Vol. 22, No. 1 [2012], Art. 1

https://commons.erau.edu/jaaer/vol22/iss1/1 